\title{
Macular sensitivity after half-dose verteporfin photodynamic therapy in central serous chorioretinopathy
}

This article was published in the following Dove Press journal:

Clinical Ophthalmology

I December 2015

Number of times this article has been viewed

\section{Thuss Sanguansak \\ Prapapan Pitujaturont \\ Yosanan Yospaiboon \\ Suthasinee Sinawat \\ Tanapat Ratanapakorn \\ Chavakij Bhoomibunchoo \\ Department of Ophthalmology, Faculty of Medicine, KKU Eye Center, Khon Kaen University, Khon Kaen, Thailand}

Objective: To study the macular sensitivity after half-dose verteporfin photodynamic therapy in patients with resolved central serous chorioretinopathy using the automated static perimeter.

Methods: Prospective consecutive case study of 24 patients with resolved central serous chorioretinopathy was performed. The macular sensitivity was measured using a conventional automated static perimeter with the Swedish interactive threshold algorithm 10-2 and foveal threshold. Best corrected visual acuity, intraocular pressure, fundus examination, macular thickness, and volume were also examined. The mean macular sensitivities of the affected eyes and their normal fellow eyes were calculated and compared. $P<0.05$ was considered statistically significant.

Results: The mean macular sensitivities of the affected eyes were lower than the normal fellow eyes with a statistically significant difference in all areas of the study $(P<0.05)$. Best corrected visual acuity improved significantly from pretreatment $(0.26 \pm 0.3 \operatorname{logMAR})$ to posttreatment $(0.075 \pm 0.15$ $\log$ MAR, $P<0.05)$. Macular thicknesses in affected eyes were $230.66 \pm 67.34 \mu \mathrm{m}$ and in the normal eyes were $238.33 \pm 92.26 \mu \mathrm{m}(P=0.68)$. Macular volumes in affected eyes were $8.77 \pm 0.49$ and in the normal eyes were $8.70 \pm 0.50(P=0.60)$. These findings were not statistically significant.

Conclusion: Eyes with resolved central serous chorioretinopathy after half-dose verteporfin photodynamic therapy had lower macular sensitivity than normal fellow eyes. These findings agreed well with the previous microperimetric studies. The conventional automated static perimeter can also be used when a microperimeter is not available.

Keywords: macular sensitivity, half-dose photodynamic therapy, automated static perimeter, central serous chorioretinopathy

\section{Introduction}

The neurosensory detachment of the macula in central serous chorioritinopathy (CSCR) is commonly reported in the middle-aged males. ${ }^{1,2}$ The visual acuity (VA) is decreased, and the color perception is distorted, because the photoreceptor cells and retinal pigment epithelium (RPE) are destroyed from subretinal fluid that causes macular degeneration and RPE decompensation. ${ }^{3}$ Most of patients have conservative treatment and make spontaneous recovery. ${ }^{4}$ Only those who have prolonged duration of detachment of more than 12 weeks were treated with any interventions such as focal laser photocoagulation, anti-vascular endothelial growth factor (VEGF), or photodynamic therapy (PDT)..$^{5-10}$

PDT with verteporfin has been recently used for treating CSCR, and studies have demonstrated beneficial visual outcomes in most patients. The mechanism of action is postulated to be choriocapillaris hypoperfusion and choroidal vascular remodeling, leading to reduction in choroidal congestion and vascular leakage. In some CSCR
Correspondence: Yosanan Yospaiboon Department of Ophthalmology, Faculty of Medicine, KKU Eye Center, Khon Kaen University, I 23 Mitraparb Highway, Khon Kaen 40002, Thailand

Tel +6643348383

Email yosanan@kku.ac.th 
patients who have juxtafoveal or subfoveal leakage, it is hard to apply laser photocoagulation. Hence, PDT with verteporfin may have benefit for these patients in which it reduces the choroidal vascular hyperpermeability and promotes decreased leakage in the leaking area. ${ }^{7}$ The conventional PDT in CSCR patients, however, can result in potential complications such as RPE atrophy, choroidal ischemia, and secondary choroidal neovascularization (CNV). ${ }^{8,9}$ Half-dose verteporfin photodynamic therapy (HD-PDT) has been reported to minimize this potential chorioretinal damage. ${ }^{10}$

Previous microperimetric studies showed that eyes with resolved CSCR had lower retinal sensitivity in the central macula than control eyes, ${ }^{11-13}$ and there is a significant improvement in the macular sensitivity after HD-PDT when compared with the sensitivity before PDT treatment. ${ }^{14-16}$ Because there was a significant correlation between microperimetry and automated static perimetry, ${ }^{17}$ it was hypothesized that the automated static perimeter, that is more commonly available in general practice, can be used to study macular sensitivity when a microperimeter is not available. Therefore, it was proposed to study the macular sensitivity after HD-PDT in patients with resolved CSCR using the automated static perimeter.

\section{Methods}

This study was performed in accordance with the tenets of the Declaration of Helsinki and was approved by Khon Kaen University Ethics Committee (Khon Kaen, Thailand) for human research (HE551117). Patients who had been diagnosed chronic CSCR and treated with HD-PDT at the KKU eye center from January 2012 until January 2014 were recruited for this study. Patients were older than 18 years old and had normal VA in the normal eyes, and were followed for at least 6 months. Those who had ocular diseases or previous ocular surgery were excluded. All study participants signed the informed consent forms.

All patients had unilateral CSCR and were treated with HD-PDT. Eyes with resolved CSCR were the study eyes and their normal fellow eyes were the control eyes. Patients had complete ocular examinations, which included the best corrected visual acuity (BCVA) with a Snellen chart that was converted to logarithm of the minimum angle of resolution (logMAR), intraocular pressures with Goldmann applanation tonometer, fundus examinations, macular thickness measurements, and volumes with an optical coherence tomographer (Spectralis, Heidelberg Engineering, Heidelberg, Germany). The macular sensitivity was measured using conventional automated static perimeter with the Swedish interactive threshold algorithm 10-2 and foveal threshold (Humphrey 750i field analyzer, Carl Zeiss Meditec, Dublin,

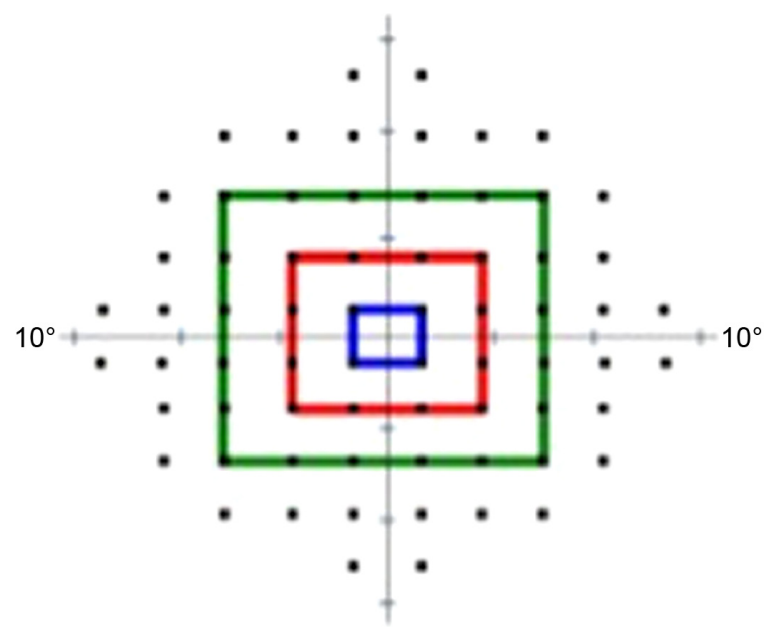

Figure I The areas to measure the macular sensitivity: center (foveal threshold), four points (blue line), 16 points (red line), and 36 points (green line) from fixation point.

CA, USA). The 68 stimulus points covering the central $10^{\circ}$ in diameter were used. The mean macular sensitivities were then calculated in four different areas: center (foveal threshold), four points $\left(1^{\circ}\right)$ in a blue line, 16 points $\left(3^{\circ}\right)$ in a red line, and 36 points $\left(5^{\circ}\right)$ in a green line (Figure 1$)$. The macular sensitivities were also calculated in four different quadrants: superotemporal, superonasal, inferotemporal, and inferotemporal from the fixation point covering the central $10^{\circ}$ (Figure 2).

PDT was performed using a $3 \mathrm{mg} / \mathrm{m}^{2}$ body surface area for the verteporfin dosage (Visudyne, Novartis International AG, Bülach, Switzerland) which is half the conventional dose of verteporfin. Verteporfin was infused over a 10-minute period followed by delivery of $50 \mathrm{~J} / \mathrm{cm}^{2}$ from a $689 \mathrm{~nm}$ laser system (Carl Zeiss Meditec) over an 83-second exposure period. The size of the laser spot was the diameter of the region of indocyanine green hyperpermeability.

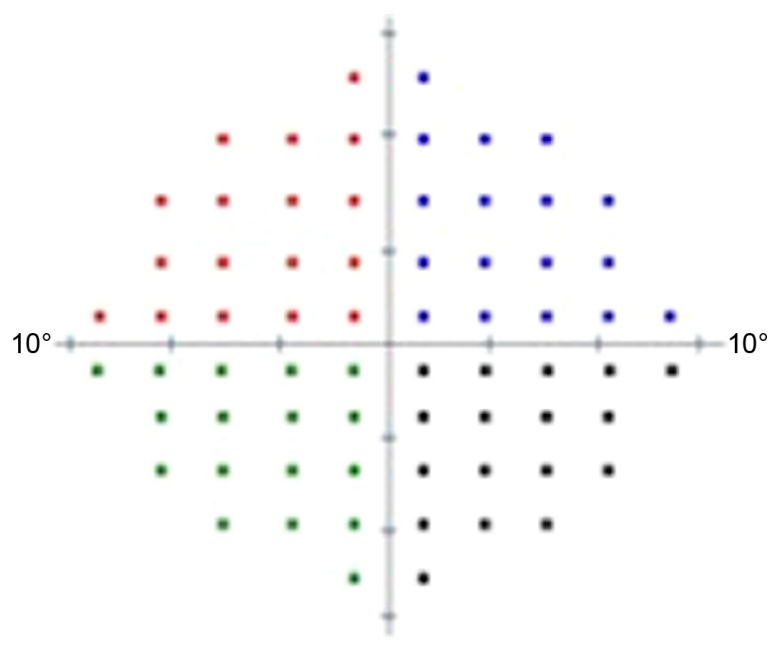

Figure 2 The areas to measure the macular sensitivity: superotemporal, superonasal, inferotemporal, and inferotemporal from fixation point. 
The Stata for Windows, version 10 was used for the statistical analysis. The mean retinal sensitivity, macular thickness, and macular volume of the study eyes were compared with the control eyes using paired Student's $t$-test. The BCVA before and after HD-PDT was also compared using paired $t$-test. $P<0.05$ was considered statistically significant.

\section{Results}

Of the 24 affected eyes in 24 patients recruited for the study, 15 eyes were on the left side. Seventeen patients were male, and the median age was 46 years old (36-68 years). The median duration of pre-PDT was 32 weeks (15-96 weeks) and post-PDT was 126 weeks (48-216 weeks). The demographic and clinical data of the patients are shown in Table 1.

BCVA improved significantly from pretreatment $(0.26 \pm 0.3 \log \mathrm{MAR})$ to posttreatment $(0.075 \pm 0.15 \log \mathrm{MAR}$, $P<0.05)$. The mean macular sensitivities in each area of the study are shown in Table 2 . It was noted that the eyes with resolved CSCR after HD-PDT have lower macular sensitivity than their normal fellow eyes with a statistically significant difference.

Macular thicknesses of the study eyes were $230.66 \pm$ $67.34 \mu \mathrm{m}$, and of the normal eyes were $238.33 \pm 92.26 \mu \mathrm{m}$ $(P=0.68)$. Macular volumes in study eyes were $8.77 \pm 0.49$, and normal eyes were $8.70 \pm 0.50(P=0.60)$. These findings were not statistically significant. Five patients had loss the inner segment/outer segment (IS/OS) junction, two patients had persistent subretinal fluid, and two patients presented with pigment epithelial detachment (PED).

\section{Discussion}

Many modalities of treatment are used for visual improvement in patients with CSCR although most of the patients

Table I Demographic and clinical characteristics of the patients $(n=24)$

\begin{tabular}{ll}
\hline Characteristics & Data \\
\hline Demographic data & \\
Age (median, min-max) years & $46,36-68$ \\
Sex: male/female & $17 / 7$ \\
Laterality: right eye/left eye & $15 / 9$ \\
Education above high school (number of patients) & 7 \\
Clinical characteristics & \\
Duration before PDT (median, min-max) weeks & $32,15-96$ \\
Duration after PDT (median, min-max) weeks & $126,48-216$ \\
Site of leakage: subfoveal leakage & 2 \\
$\quad$ Juxtafoveal leakage & 19 \\
$\quad$ Extrafoveal leakage & 3 \\
Spot size (median, min-max) $\mu \mathrm{m}$ & $2,216,1,089-4,398$ \\
\hline Abbreviations: PDT, photodynamic therapy; min, minimum; max, maximum.
\end{tabular}

Table 2 The comparative mean macular sensitivities in study and control eyes: four lines; foveal threshold, four, 16, and 36 points from fixation and four areas; superotemporal, superonasal, inferotemporal, and inferonasal areas

\begin{tabular}{llll}
\hline Study areas & \multicolumn{2}{l}{ Mean macular sensitivity } & $P$-value \\
\cline { 2 - 3 } & $\begin{array}{l}\text { Study eyes } \\
\text { (decibel) }\end{array}$ & $\begin{array}{l}\text { Control eyes } \\
\text { (decibel) }\end{array}$ & \\
\hline Center: foveal threshold & $28.75 \pm 6.52$ & $32.33 \pm 3.35$ & $<0.00 \mathrm{I}$ \\
Blue line, four points & $29.27 \pm 3.33$ & $30.92 \pm I .49$ & $<0.00 \mathrm{I}$ \\
Red line, I6 points & $29.28 \pm 3.34$ & $31.02 \pm \mathrm{I} .67$ & $<0.00 \mathrm{I}$ \\
Green line, 36 points & $28.85 \pm 3.22$ & $30.67 \pm \mathrm{I} .65$ & $<0.00 \mathrm{I}$ \\
Superotemporal area & $28.56 \pm 3.0 \mathrm{I}$ & $30.43 \pm \mathrm{I} .15$ & $<0.00 \mathrm{I}$ \\
Superonasal area & $28.23 \pm 3.18$ & $30.22 \pm \mathrm{I} .2 \mathrm{I}$ & $<0.00 \mathrm{I}$ \\
Inferotemporal area & $29.1 \mathrm{I} \pm 2.86$ & $30.8 \mathrm{I} \pm \mathrm{I} .49$ & $<0.00 \mathrm{I}$ \\
Inferonasal area & $29.35 \pm 2.02$ & $30.44 \pm \mathrm{I} .49$ & 0.002 \\
\hline
\end{tabular}

Note: Data presented as mean \pm SD.

resolved spontaneously. Several studies have reported that patients treated with PDT have favorable outcomes both anatomically and functionally. ${ }^{7-10}$ Maruko et al evaluated the subfoveal choroidal thickness after PDT treatment of CSCR, visualized by enhanced depth imaging spectral domain optical coherence tomography. They demonstrated that the choroidal thickness was reduced after PDT and suggested that PDT may reduce the choroidal vascular hyperpermeability in CSC. ${ }^{7}$ Potential complications after PDT such as RPE atrophy, choroidal ischemia, and secondary CNV had been reported. ${ }^{8,9}$ All these complications affected the macular sensitivity. Chan et al ${ }^{10}$ reported HD-PDT for CSCR patients to minimize these chorioretinal damages. They demonstrated that decreasing the dose of verteporfin to be half-dose maintained its efficacy and improved safety.

This study demonstrates that using the automated static perimeter, eyes with resolved CSCR after HD-PDT, have lower retinal sensitivity in the central macula than their normal fellow eyes with a statistically significant difference. This finding agrees well with the previous microperimetric studies. Ozdemir et a ${ }^{11}$ studied macular function by microperimetry in eyes with CSCR and showed significantly lower retinal sensitivity not only at the central but also in the paracentral area. They also showed that eyes with resolved CSCR had lower retinal sensitivity in the central macula than control eyes, even after good VA has been obtained. ${ }^{12}$ Ojima et a ${ }^{13}$ measured retinal sensitivity with microperimeter 1 after resolution of CSCR and reported that eyes with resolved CSCR had focal areas with reduced retinal function, which is consistent with irregularity of the RPE or with defects of the IS/OS.

Sekine et a ${ }^{18}$ studied the retinal sensitivity in eyes with untreated CSCR using automated static perimeters. They demonstrated lower retinal sensitivity in the central macula 
and proposed that macular sensitivity was attenuated by increasing the distance between the photoreceptor and RPE. Springer et al ${ }^{17}$ performed static threshold perimetry in 30 healthy volunteers comparing between the microperimeter and automated static perimeter and demonstrated that sensitivity values in microperimetry are comparable to the threshold values obtained with the automated static perimeter (Octopus 101). Therefore, automated static perimetry can be used to measure the macular sensitivity when a microperimeter was not available.

This study revealed comparative point-to-point macular sensitivity in both CSCR and normal fellow eyes with the automated static perimeter, and demonstrated the decrease in macular sensitivity in all areas that HD-PDT was applied despite good anatomic reattachment and normal VA. This may be explained by the result of the photoreceptors and RPE damage from chronic macular detachment. PDT itself had also been reported to cause RPE damage. ${ }^{9}$ Therefore, the reduced macular sensitivity may be affected from both chronic macular detachment and PDT.

Although many published papers have shown that PDT gave good visual results in acute and chronic CSCR, ${ }^{7-10}$ there were also some risks of developing $\mathrm{CNV}$, choroidal ischemia, RPE atrophy, PED, RPE rip, and loss of the IS/ OS junction. ${ }^{8,9,19,20}$ These late complications need to be monitored in long-term follow-up. Either microperimeter or automated static perimeter can be used. Because the latter is more commonly available in general practice, it is an alternative to use in monitoring these CSCR patients.

\section{Conclusion}

Eyes with resolved CSCR after HD-PDT had lower retinal sensitivity in the central macula than in normal fellow eyes. This finding agrees well with the previous microperimetric studies. A conventional automated static perimeter can also be used when a microperimeter is not available.

\section{Acknowledgments}

The authors thank Dr Kaewjai Thepsuthammarat, Clinical Epidemiology Unit, Faculty of Medicine, Khon Kaen University for statistical analysis and Professor James A Will, University of Wisconsin for assistance with the Englishlanguage presentation of the manuscript.

\section{Disclosure}

The authors report no conflicts of interest in this work.

\section{References}

1. Wang M, Munch IC, Hasler PW, Prünte C, Larsen M. Central serious retinopathy. Acta Ophthalmol. 2008;86(2):126-145.

2. Ross A, Ross AH, Mohamed Q. Review and update of central serious chlorioretinopathy. Curr Opin Ophthalmol. 2011;22(3):166-173.

3. Wang M, Sander B, Ia Cour M, Larsen M. Clinical characteristics of subretinal deposit in central sereous chorioretinopathy. Acta Ophthalmol Scand. 2005;83(6):691-696.

4. Castro-Correia J, Coutinho MF, Rosas V, Maria J. Long term follow up central serious retinopathy in 150 patients. Doc Ophthalmol. 1992; 81(4):379-386.

5. Burumcek E, Mudun A, Karacorlu S, Arslan MO. Laser photocoagulation for persistent central sereous retinopathy: result of long-term follow-up. Ophthalmology. 1997;104(4):616-622.

6. Schaal KB, Hoeh AE, Scheuerle A, Schuett F, Dithmar S. Intravitreal bevacizumab for treatment of chronic central serous chorioretinopathy. Eur J Ophthalmol. 2009;19(4):613-617.

7. Maruko I, lida T, Sugano Y, Ojima A, Ogasawara M, Spaide RF. Subfoveal choroidal thickness after treatment of central serous chorioretinopathy. Ophthalmology. 2010;117(9):1792-1799.

8. Cardillo Piccolino F, Eandi CM, Ventre L, Rigault de la Longrais RC, Grignolo FM. Photodynamic therapy for chronic central serous chorioretinopathy. Retina. 2003;23(6):752-763.

9. Colucciello M. Choroidal neovascularization complicating photodynamic therapy for central serous chorioretinopathy. Retina. 2006;26: 239-242.

10. Chan WM, Lai TY, Lai RY, Liu RY, Lam DS. Half-dose verteporfin photodynamic therapy for acute central serous chorioretinopathy: oneyear results of a randomized controlled trial. Ophthalmology. 2008; 115(10):1756-1765.

11. Ozdemir H, Karacorlu SA, Senturk F, Karacorlu M, Uysal O. Assessment of macular function by microperimetry in unilateral resolved central serous chorioretinopathy. Eye (Lond.). 2008;22(2):204-208.

12. Ozdemir H, Senturk F, Karacorlu M, Arf Karacorlu S, Uysal O. Macular sensitivity in eyes with central serous chorioretinopathy. Eur J Ophthalmol. 2008;18(5):799-804.

13. Ojima Y, Tsujikawa A, Hangai M, et al. Retinal sensitivity measured with the micro perimeter 1 after resolution of central serous chorioretinopathy. Am J Ophthalmol. 2008;146(1):77-84.

14. Senturk F, Karacorlu M, Ozdemir H, Karacorlu SA, Uysal O. Microperimetric changes after photodynamic therapy for central serous chorioretinopathy. Am J Ophthalmol. 2011;151:303-309.

15. Fujita K, Yuzawa M, Mori R. Retinal sensitivity after photodynamic therapy with half-dose verteporfin for chronic central serous chorioretinopathy: short-term results. Retina. 2011;31:772-778.

16. Fujita K, Shinoda K, Imamura Y, et al. Correlation of integrity of cone outer segment tips line with retinal sensitivity after half-dose photodynamic therapy for chronic central serous chorioretinopathy. Am J Ophthalmol. 2012;154(3):579-585.

17. Springer C, Bültmann S, Völcker HE, Rohrschneider K. Fundus perimetry with the micro perimeter 1 in normal individuals: comparison with conventional threshold perimetry. Ophthalmology. 2005;112(5): 848-854.

18. Sekine A, Imasawa M, Iijima H. Retinal thickness and perimetric sensitivity in central serous chorioretinopathy. Jpn J Ophthalmol. 2010; 54(6):578-583.

19. Leng T, Sanislo SR, Jack RL. Photodynamic therapy rescue for subretinal fluid exacerbation after focal laser treatment in idiopathic central serous chorioretinopathy. Open Ophthalmol J. 2011;5:6-9.

20. Ratanasukon M, Thongthong K, Bhurayanontachai $P$, Jirarattanasopa $P$. Photoreceptor disruption in central serous chorioretinopathy treated by half-dose photodynamic therapy. Clin Ophthalmol. 2013;7:87-92. 
Clinical Ophthalmology

\section{Publish your work in this journal}

Clinical Ophthalmology is an international, peer-reviewed journal covering all subspecialties within ophthalmology. Key topics include: Optometry; Visual science; Pharmacology and drug therapy in eye diseases; Basic Sciences; Primary and Secondary eye care; Patien Safety and Quality of Care Improvements. This journal is indexed on

PubMed Central and CAS, and is the official journal of The Society of Clinical Ophthalmology (SCO). The manuscript management system is completely online and includes a very quick and fair peer-review system, which is all easy to use. Visit http://www.dovepress.com/ testimonials.php to read real quotes from published authors. 